\title{
Multi-source analysis of severe convection weather induced by a supercell storm in Hengshui
}

Hao Song

Hengshui Meteorological observation center

Hengshui, China

15610890001@126.com
Yuting Zhang

Hengshui Meteorological Observatory

Hengshui, China

18731858119@163.com

\section{衡水市某超级单体风暴引发强对流天气} 的多源资料分析

宋影

衡水市气象探测中心

衡水, 中国

15610890001@126.com
张玉婷

衡水市气象台

衡水, 中国

18731858119@163.com
Abstract-The severe convection weather induced by a supercell storm in Hengshui from north to south on June $13^{\text {th }}, 2018$ was analyzed by using the meteorological data from MICAPS, the data of the microwave radiometer from Hengshui Meteorological Bureau, the data of wind-profiling radar in Jizhou District of Hengshui, the data of the Doppler radar in Shijiazhuang, and the data of the dual polarization radar in Raoyang County of Hengshui. The results showed thatthe process was a severe convective weather triggered by a supercell storm, which triggered by the intersection of high-level dry and cold air with low-level warm and humid air in the rear of a vortex , and was dominated by hail, thunderstorm and strong wind. Hengshui had maintained an unstable stratification with cold-dry air on the top and warm-humid air on the bottom before the storm was born. The $0^{\circ} \mathrm{C}$ layer and the $-20^{\circ} \mathrm{C}$ layer were at suitable heights, thus providing a favorable environment for the occurrence and development of severe convection. The northerly wind current in the middle and upper levels had played a good role in pumping and ventilating the current, which increased the transportation of cold and dry air in the middle and upper levels, thereby further increasing the vertical wind shear in the upper and lower levels, and eventually causing the stratification to became even less stable. As the low-level shear line transited, the unstable energy was triggered, which in turn maintainedthe strength of the severe convective weather. The data of the dual-polarized radarcould better describe the particle size, particle shape, and precipitation type, as well as detect and warn of the hail area. By integrating the data of the dual-polarized radar and the Doppler radar, early warning signals of hail could be sent about 66 minutes earlier.

Keywords - supercell storm, hail, microwave radiometer, wind-profiling radar, doppler radar, dual polarization radar

摘要一利用 micaps 气象资料以及衡水市气象局微 波辐射计资料、衡水市冀州区风廓线雷达资料、石 家庄市多普勒雷达资料、衡水市饶阳县双偏振雷达 资料对 2018 年 6 月 13 日衡水市自北向南出现的一 次超级单体风暴引发强对流天气过程进行分析。结 果表明: 此次过程是一次浴槽后部高层干冷空气与 低层暖湿气流交汇触发超级单体风暴引发的强对 
流天气, 主要以冰雹、雷暴大风为主。风暴生成前 衡水地区一直维持上干冷、下暖湿的不稳定层结, $0^{\circ} \mathrm{C}$ 层与 $-20^{\circ} \mathrm{C}$ 层高度合适, 为超级单体风暴的发生 发展提供了有利的环境。中高层的偏北风急流起到 了很好的抽吸和通风作用, 增加了中高层干冷空气 的输送, 使高低空垂直风切变进一步增大, 层结更 加不稳定。低层切变线过境, 触发了近地面的不稳 定能量, 使超级单体风暴得以维持。双偏振雷达资 料可更好地描述粒子的尺寸、形状以及降水类型, 还可以探测和预警冰雹区域, 在此次过程中, 将其 与多普勒雷达资料结合分析, 可使冰霄预警信号的 提前量达到 66 分钟左右。

关键词一超级单体风暴, 冰雨, 微波辐射计, 风廓 线雷达, 多普勒雷达, 双偏振雷达

\section{I. 引言}

强对流天气是指短时强降水、雷暴大风、 冰雱、龙卷等破坏性天气, 多发生于中小尺度 天气系统。其中, 与超级单体相伴随的强对流 天气则具有持续时间长、灾害范围广、发展最 为猛烈等特点。“超级单体 (superce11)”一 词是 Browning ${ }^{[1]}$ 于 1962 年在研究发生在英国 的一次强对流风暴时提出的, 代表该风暴在其 最强盛期间的准稳定状态。Marwitz（1972） ${ }^{[2]}$ 以及 Chi sholm 和 Renick（1972） ${ }^{[3]}$ 正式提 出将超级单体作为局地对流风暴的一种类型, 超级单体一词作为一种风暴类型的代表才被 广泛使用。

夏季衡水市强对流天气频发, 本文利用 2018 年 6 月 13 日 MICAPS 气象资料以及石家 庄多普勒雷达资料、衡水市气象局微波辐射计 资料、衡水市饶阳县双偏振雷达资料、衡水市 冀州区风廓线雷达资料等对此次超级单体引 发强对流天气进行分析, 旨在提高对强对流天 气的认识，提高强对流天气预报预警准确率。

\section{II. 资料与方法}

本文所使用的资料为 2018 年 6 月 13 日 micaps 气象资料以及石家庄多普勒雷达资料、 衡水市气象局微波辐射计资料、衡水市饶阳县 双偏振雷达资料、衡水市冀州区风廓线雷达资 料, 图 1a 为各类探测仪器的地理分布。因邢 台探空位置偏南, 不能很好地指示此次强对流 天气发生前后的大气层结情况, 因此此次过程 分析未采用。
III. 天气实况

2018 年 6 月 13 日下午, 衡水市自北向南 出现强对流天气 (图 1a), 主要以冰雹、雷暴、 大风为主 (图 1b)。其中共有四个县 (市、区) 出现冰雨, 分别为安平县 $(16: 08)$ 、深州市

(16:30)、衡水市区 $(17: 01)$ 、冀州区 $(17: 24)$, 最大直径 $2.2 \mathrm{~cm}$, 四个县市出现雷暴, 分别为 饶阳县 $(15: 57)$ 、安平县 $(16: 04)$ 、深州市

(16:15)、武强县 (16:18), 深州市出现 $22 \mathrm{~m} / \mathrm{s}$ 的大风 (另安平 $16 \mathrm{~m} / \mathrm{s}$ 、饶阳 $15.4 \mathrm{~m} / \mathrm{s}$ 、衡水 $12 \mathrm{~m} / \mathrm{s}$ 、冀州 $16.3 \mathrm{~m} / \mathrm{s}$ )。

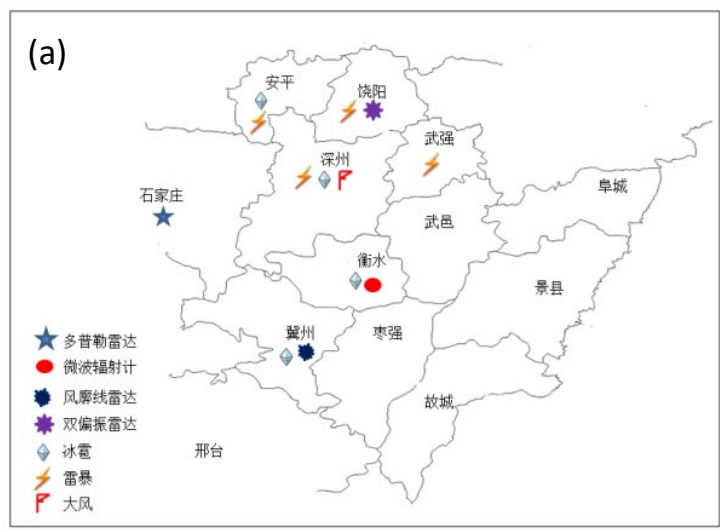

\begin{tabular}{|c|c|c|c|c|c|}
\hline \multicolumn{6}{|c|}{ 泥圠禹要天气报数据 } \\
\hline & & 站各 & 地区 & 天气 & 详情 \\
\hline 61 & 54606 & 畮阳 & 河北肖 & 雷港 & 15 点 57 分出现雷港 \\
\hline 62 & 54609 & 安平 & 河北首 & 雷暴 & 16点04分出现雷昆 \\
\hline 63 & 54626 & 肃宁 & 河北肖 & 雷港 & 16 点 04 分出现雷港 \\
\hline 64 & 54609 & 安平 & 河北首 & 冰電 & 16 点08分出现水電 $1.4 \mathrm{~cm}$ \\
\hline 65 & 53688 & 行唐 & 河北首 & 大风 & 16 点 10 分在 70 度方位, 姿时风力达到 $18 \mathrm{~m} / \mathrm{s}$ \\
\hline 66 & 54608 & 深州 & 河北肖 & 雷暴 & 16点15分出现雷暴 \\
\hline 67 & 54700 & 试强 & 河北肖 & 雷港 & 16点18分出现雷港 \\
\hline 68 & 54608 & 深州 & 河北首 & 冰番 & 16 点 30 分出现水毛 $0.6 \mathrm{~cm}$ \\
\hline 69 & 54608 & 深州 & 河北首 & 大风 & $\begin{array}{l}16 \text { 点 } 31 \text { 分在 } 360 \text { 度方位，楿时风力达到 } \\
22 \mathrm{~m} / \mathrm{s}\end{array}$ \\
\hline 70 & 54702 & 翻水 & 河北首 & 冰電 & 17 点 01 分出现水電 $0.8 \mathrm{~cm}$ \\
\hline 71 & 54704 & 美州 & 河北肖 & 冰電 & 17 点 24 分出现水番 $2.2 \mathrm{~cm}$ \\
\hline
\end{tabular}

图 12018 年 6 月 13 日衡水市强对流天气实况

IV. 大尺度环流背景和影响系统分析

从 2018 年 6 月 13 日 08 时的形势场来看, 高空 $500 \mathrm{hPa}$ （图 2a）河北省北部与内蒙古交 界处有一低浴, 槽位于我省北部一山东一带, 我市处于浴底槽后西北气流影响, $700 \mathrm{hPa}$ （图 $2 \mathrm{~b}$ ) 在河北省北部到南部地区有一南北向切变, $850 \mathrm{hPa}$ (图 2c) 切变线与 $700 \mathrm{hPa}$ 切变线基本 垂直。但中低层切变线的位置明显偏后于 $500 \mathrm{hPa}$ 槽线位置, 高低层系统为前倾结构, 有利于强对流天气出现。地面（图 2d）我市 为东北风, 在河北省中南部地区有一低压, 倒 
槽压在河北省中北部地区, 有利于辐合上升运 动。
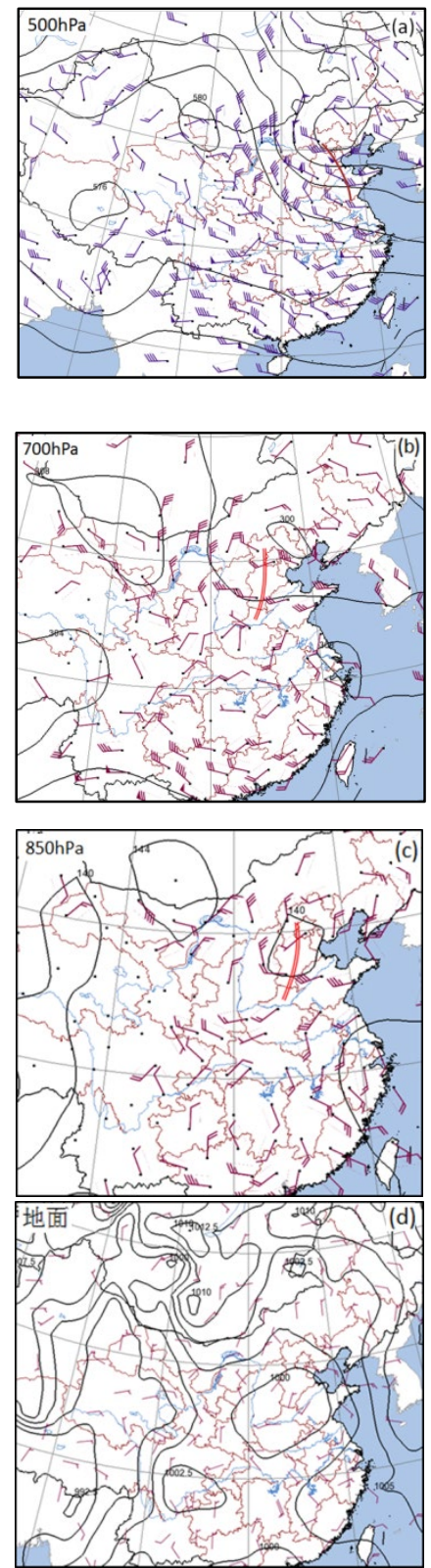

图 22018 年 6 月 13 日 08 时形势场

6 月 13 日 14 时，系统继续东移，前倾结 构依旧维持, $700 \mathrm{hPa}$ 与 $850 \mathrm{hPa}$ 切变线从我市 移过，地面（图 3) 我市依旧维持东北风，倒 槽南压至河北省中南部地区, 辐合上升运动增 强。低层系统过境, 对降雨有明显的触发作用。

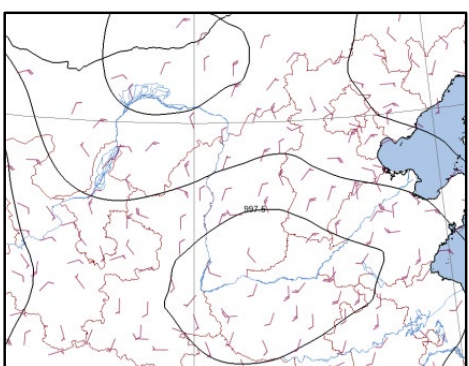

图 32018 年 6 月 13 日 14 时地面图

V. 微波辐射计资料分析
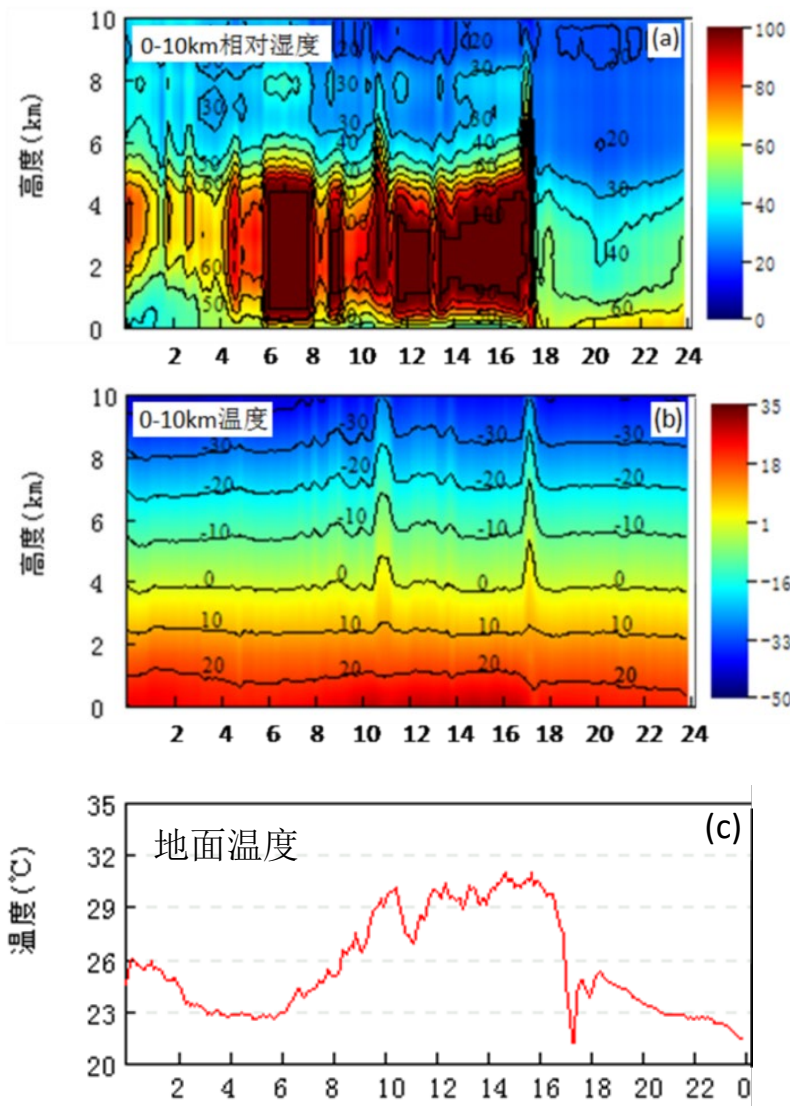

图 42018 年 6 月 13 日微波辐射计资料

为了解降雨前后衡水地区的高低空层结 情况，对衡水市气象局的微波辐射计资料进行 分析 ${ }^{[4]}$ 。从 2018 年 6 月 13 日微波辐射计相对 湿度时空序列图上来看 (图 4a)，从 13 日 04 时开始, $0-5 \mathrm{~km}$ 附近高度上的相对湿度有一个 明显的增大，06 时以后相对湿度接近 100\%, 而 $5 \mathrm{~km}$ 以上相对湿度则一直较低, 维持在 30-40\%左右; 另外, 从温度时空序列图上来看 (图 4b), $4 \mathrm{~km}$ 以下温度一直维持在 $0^{\circ} \mathrm{C}$ 以上, 尤其是 12 时以后, 地面温度一直在 $30^{\circ} \mathrm{C}$ 以上 (图 4c)。因此, 13 日 06 时以后, 衡水市一 直维持上干冷、下暖湿的不稳定层结, 有利于 雷暴大风的出现。另外, $0^{\circ} \mathrm{C}$ 层高度在 $4 \mathrm{~km}$ 附 
近, $-20^{\circ} \mathrm{C}$ 层高度在 $7 \mathrm{~km}$ 附近; 地面为东北风, 高空则为较大的西北风, 垂直风切变较大, 有 利于冰雹的出现。因此, 衡水地区的层结很利 于出现强对流天气。

\section{VI. 风廓线雷达资料分析}

为了了解降雨前后冷空气活动情况及衡 水市上空风场垂直变化结构, 对衡水市冀州区 风廓线雷达资料进行分析 ${ }^{[5]} 。 14: 18$ 之前, $500 \mathrm{~m}$ 以下风随高度顺转, 表明冀州区上空近地面层 为弱的暖平流, $500 \mathrm{~m}$ 以上风随高度逆转, 表 明上层有冷平流。在 $5.5 \mathrm{~km}$ 附近有 $20 \mathrm{~m} / \mathrm{s}$ 的大 风速带一直维持, 起到了很好的抽吸和通风作 用, $3 \mathrm{~km}$ 附近有 $18 \mathrm{~m} / \mathrm{s}$ 的偏北风低空急流, 二 者增加了中高层干冷空气的输送, 使高低空垂 直风切变进一步增大, 层结更加不稳定。17:18 前后, 1-1. $5 \mathrm{~km}$ 附近有切变线过境, 触发了冀 州区的不稳定能量, 使强对流天气维持, 17:24 冀州区开始降雹。
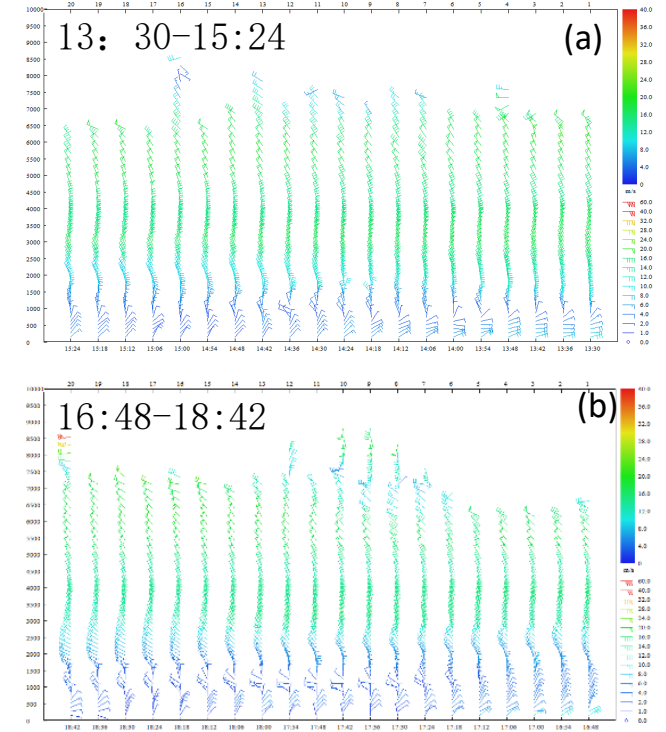

图 52018 年 6 月 13 日风廓线雷达资料

\section{VII. 卫星云图资料分析}

为了解此次衡水地区强对流天气对流云 团的基本特征, 对 FY2E 卫星云图资料进行分 析。从红外云图来看, 13 日 13 时在北京南部 附近有一对流云团产生, 随后向南移动并有所 加强。16 时, 此对流云团开始影响衡水市。 从 17 时（图 6) 红外云图来看, 对流云团云 顶亮温达到 $220^{\circ} \mathrm{K}$, 为一发展强盛的积雨云, 在对流云团的西南侧已经出现 “V” 型结构, 说明此积雨云为一雨暴云; 从可见光图像及水
汽图像来看, 此雱暴云团出现上冲云顶和暗影, 并且水汽含量较多, 发展旺盛。1 8 时此云团 移出衡水市并开始减弱消散。

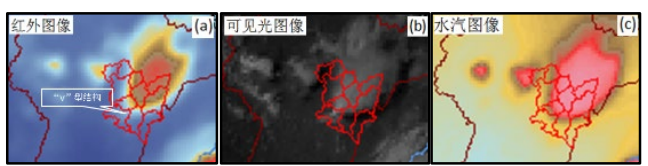

图 62018 年 6 月 13 日 17 时 FY2E 云图资料

VIII. 多普勒雷达资料分析

为详细了解此次过程影响系统的中小尺 度特征, 对离系统较近的石家庄多普勒雷达资 料进行分析 ${ }^{[6]}$ 。2018 年 6 月 13 日下午, 有一 孤立的雷暴单体从保定地区生成, 随后由北向 南移动。1 $4: 48$ 此雷暴单体加强成为超级单体

（图 7): 从基本反射率因子图中可以看到回 波最强处已达到 $55 \mathrm{dBZ}$, 并且出现较为明显的 钩状回波和三体散射长钉, 说明此时对流单体 已经逐渐开始具有冰霖的回波特征; 从剖面图 中可以看出, $50 \mathrm{dBZ}$ 的强回波已经发展到 $9 \mathrm{~km}$ 以上, 远高于 $-20^{\circ} \mathrm{C}$ 层高度, 并且低层出现有 界弱回波区和较强的反射率因子梯度, 中高层 出现回波悬垂, 有利于冰雹的形成; 从垂直累 积液态水 (VIL) 图中可以看出, 初期有 VIL 值从 $25 \mathrm{~kg} / \mathrm{m}^{2}$ 向 $45 \mathrm{~kg} / \mathrm{m}^{2}$ 跃增, 对冰雱的形成 有指示作用; 从基本速度图中可以看出, 低层 出现 $17.5 \mathrm{~m} / \mathrm{s}$ 的径向速度, 并且弱的中气旋开 始形成并发展, 转动速度达到 $10 \mathrm{~m} / \mathrm{s}$, 加大了 出现雷暴大风的潜势。这说明此超级单体可出 现冰雨、雷暴大风等强对流天气。

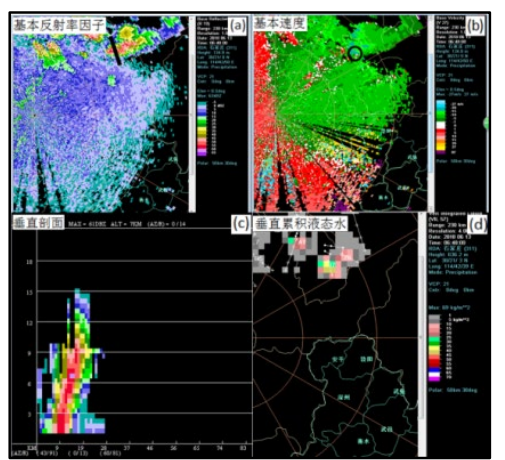

图 72018 年 6 月 13 日 14:48 多普勒雷达资料 随后, 此超级单体由北向南移动并有所加 强, 15:54 开始影响我市, 15:57 饶阳县出现 雷暴, $16: 04$ 安平县出现雷暴, $16: 08$ 安平县 出现冰霞。从 2018 年 6 月 13 日 16:06 石家庄 多普勒雷达资料来看, 基本反射率因子最强处 达到 $65 \mathrm{dBZ}$ ，钩状回波和三体散射长钉更加明 
显, $50 \mathrm{dBZ}$ 的强回波依旧维持在 $9 \mathrm{~km}$ 以上, 低 层有界弱回波区、反射率因子强梯度和中高层 回波悬垂更加清晰, 垂直累积液态水 (VIL) 达到 $60 \mathrm{~kg} / \mathrm{m}^{2}$, 中气旋转动速度维持在 $10 \mathrm{~m} / \mathrm{s}$ 左右, 以上各指标均指示可出现冰雨、雷暴大 风等强对流天气。

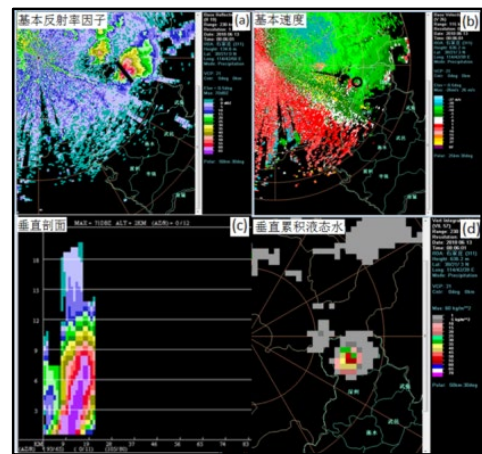

图 82018 年 6 月 13 日 16:06 多普勒雷达资料

$16: 12$ 此超级单体开始影响深州市, $16: 30$ 深州市出现冰雹, $16: 31$ 深州市出现 $22 \mathrm{~m} / \mathrm{s}$ 大风。从 2018 年 6 月 13 日 16:30石家 庄多普勒雷达资料来看, 基本反射率因子最大 值、钩状回波和三体散射长钉、 $50 \mathrm{dBZ}$ 的强回 波高度、低层有界弱回波区、反射率因子强梯 度以及中高层回波悬垂与 16:06 相比变化不 大, 指示冰雹天气继续维持。但低层最大径向 速度增大至 $20 \mathrm{~m} / \mathrm{s}$ 左右, 中气旋转动速度也增 大至 $15 \mathrm{~m} / \mathrm{s}$ 左右, 并且从基本反射率因子剖面 图来看, 最大反射率因子核心高度与 16:06 相 比有一个明显的下降, VIL 值也由 $60 \mathrm{~kg} / \mathrm{m}^{2}$ 降 至 $50 \mathrm{~kg} / \mathrm{m}^{2}$ ，指示地面可出现大风天气。

16:48 此超级单体开始影响衡水市区, 17:12 由市区移至冀州区, 17:36 此超级单体 在冀州区南部减弱并消散。

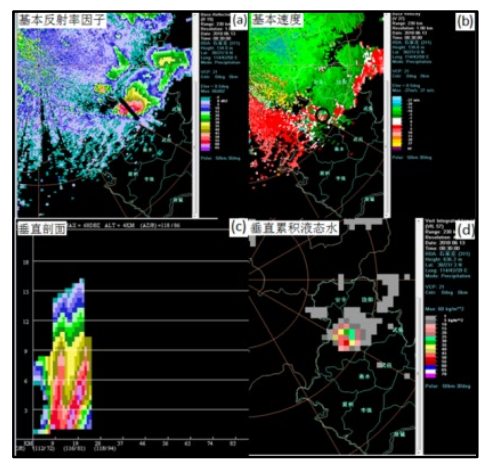

图 92018 年 6 月 13 日 16:30 多普勒雷达资料

综上所述, 此超级单体由衡水北部生成至 衡水南部消散, 共造成衡水市 4 个县(市、区)
出现冰霨、雷暴大风等强对流天气。6 $6 \mathrm{dBZ}$ 以 上的强反射率因子、钩状回波和三体散射长钉、 低层有界弱回波区和反射率因子强梯度、中高 层回波悬垂、初期 VIL 值跃增和 VIL 大值的维 持等指标可指示冰霖的出现; 低层径向速度大 值区、最大反射率因子核心高度迅速下降、VIL 值迅速下降则可指示雷暴大风的出现。

\section{IX. 双偏振雷达资料分析}

与多普勒雷达相比, 双偏振雷达除了可获 取基本反射率因子、基本速度等常规产品外, 其优势在于其可更好地描述粒子的尺寸、形状 以及降水类型。除此之外, 其还可以探测和预 警冰雹区域 ${ }^{[7-9]}$ 。

差分反射率 ZDR 定义为: $Z D R=10 \log _{10}\left[Z_{\mathrm{H}} /\right.$ $\left.Z_{\mathrm{v}}\right]$, 其中 $Z_{\mathrm{H}}$ 和 $Z_{\mathrm{v}}$ 分别为水平通道和垂直通道 的强度, 可以理解为水平通道和垂直通道的强 度差, 单位是 $\mathrm{dB}$, 比值的大小直接和粒子的 形状 (非球形) 有关。由于大雨滴呈扁的椭球 状, 故 ZDR 值可达 3-5dB; 而冰雱更接近于球 形, 因此 ZDR 值在零附近, 可以是小的负值或 小的正值。

差分传播相移率 $\mathrm{KDP}$ 定义为: $\mathrm{KDP}=[\Phi$ $\left.{ }_{\mathrm{DP}}\left(\mathrm{r}_{2}\right)-\Phi_{\mathrm{DP}}\left(\mathrm{r}_{1}\right)\right] / 2\left(\mathrm{r}_{2}-\mathrm{r}_{1}\right)$, 也就是 $\Phi_{\mathrm{DP}}$ 在距离上 (双程) 的变化率, 该参量和液态水含量直接 相关。一般来说, 降水区中的液态水含量越多, $\mathrm{KDP}$ 值越大, 单位是 ${ }^{\circ} / \mathrm{Km}$ 。冰霖时, 一般 KDP $<1^{\circ} / \mathrm{Km}$, 但含有冰核的大雨滴时, KDP 可达 $2.5^{\circ} / \mathrm{Km}$ 。

零延迟相关系数 ROHV 表征的是同时接收 到的 $Z_{\mathrm{H}}$ 和 $Z_{\mathrm{V}}$ 之间相关程度的物理量, 水凝物 相态、形状多样时 ROHV 值较小, 在只有一种 凝聚物时 ROHV 值较大。

饶阳县双偏振雷达 14:56 开始观测到此 超级单体, 15:02 此单体移至保定市清苑附近。 从 $1.5^{\circ}$ 仰角资料可以看出, 较强的回波出现 在图中黑色圆圈处, 最强达到 55dBZ (图 10a), 此处的 ZDR 值约为 $-0.5-1.0 \mathrm{~dB}$ (图 10b), KDP 值约为 $-0.5-2.5^{\circ} / \mathrm{Km}$ (图 10c), ROHV 值约 为 0.93-0.99 (图 10d), 以上各数值皆指示此 处出现冰雨或雨夹雹。

结合双偏振雷达与多普勒雷达资料, 衡水 地区此次发布冰雹预警信号的提前量可达 66 分钟左右。 


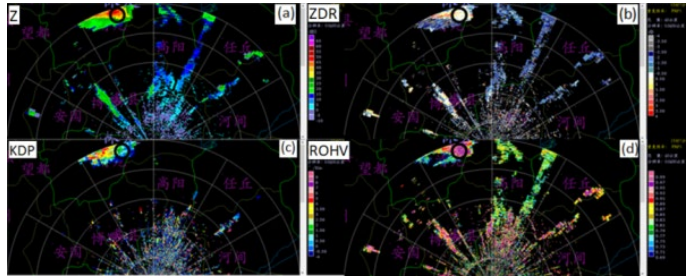

图 10 2018 年6月 13 日 15:02 双偏振雷达资料

至 16:24（图 11), 此超级单体回波较强 处移至深州北部 (图 11a), 从其垂直剖面图 上来看 (图 $11 \mathrm{~b}$ ), $2 \mathrm{~km}$ 以下出现 $65 \mathrm{dBZ}$ 以上的 强回波, 并且有明显的低层反射率因子强梯度 和回波顶偏移。 $55 \mathrm{dBZ}$ 回波高度约为 $7 \mathrm{KM}$, 与 $-20^{\circ} \mathrm{C}$ 层高度接近, 为高悬的强回波, 有利于 雹胚的形成与生长。从双偏振雷达的相态识别 结果来看 (图 11c、d), 此处粒子相态主要为 雨夹雹, 其存在的主要高度为 $2-5 \mathrm{~km}$, 另外还 存在雨滴、湿霰、干霰、不规则冰等混合粒子。

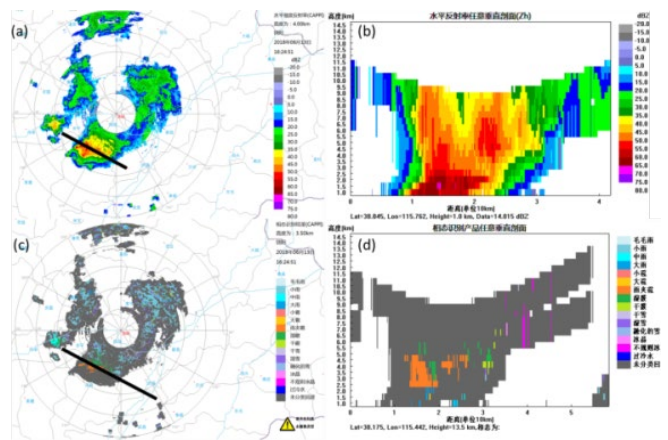

图 112018 年 6 月 13 日 16:24 双偏振雷达资料

\section{X. 结论}

此次过程是一次浴槽后部高层干冷空气与 低层暖湿气流交汇触发超级单体风暴引发的 强对流天气，主要以冰雨、雷暴大风为主。 衡水市局微波辐射计资料显示, 风暴生成前 衡水地区一直维持上干冷、下暖湿的不稳定 层结, $0^{\circ} \mathrm{C}$ 层与 $-20^{\circ} \mathrm{C}$ 层高度合适, 为超级单 体风暴的发生发展提供了有利的环境。从冀 州区风廓线雷达资料看, 中高层的偏北风急 流起到了很好的抽吸和通风作用, 增加了中 高层干冷空气的输送, 使高低空垂直风切变 进一步增大, 层结更加不稳定。低层切变线 过境, 触发了近地面的不稳定能量, 使超级 单体风暴得以维持。从多普勒雷达资料看, 此超级单体出现的 $65 \mathrm{dBZ}$ 以上的强反射率因子、 钩状回波和三体散射长钉、低层有界弱回波 区和反射率因子强梯度、中高层回波悬垂、 初期 VIL 值跃增和 VIL 大值的维持等指标可指
示冰雨的出现；低层径向速度大值区、最大 反射率因子核心高度迅速下降、VIL 值迅速下 降则可指示雷暴大风的出现。双偏振雷达资 料的优势在于其可更好地描述粒子的尺寸、 形状以及降水类型，还可以探测和预警冰霖 区域。在此次过程中，将其与多普勒雷达资 料结合分析, 可使冰雹预警信号的提前量达 到 66 分钟左右。

\section{致谢}

衰心感谢衡水市气象台各位专家的真诚帮 助, 为本课题论文的书写及讨论提供了宝贵 的意见。本课题得到了河北省科技厅 “太行 山东麓人工增雨防雨试验示范项目” 的鼎力 支持。

\section{参考文献}

[1] Browning K A, Ludlam F H. Airflow in convective storms [J]. Qum J Roy Meteor Soc , 1962, $88(1): 117-135$

[2] Marwitz J D. 1972. The structure and motion of servere hailsorms. J. APPL. Met. , 11, 166-201.

[3] Chisholm A J and Renick J H. 1972. The kinematics of multicell and supercell Alberta hailstorms, Alberta Hail Studies, 1972, Research Council of Alberta Hail Studies Rep. No. 72-2, 24-31.

[4] 刘红燕, 王迎春, 王京丽, 李炬, 曹晓彦, 熊斌. 由地基微 波辐射计测量得到的北京地区水汽特性的初步分析 [J]. 大气科学. 2009 (02)

[5]董保举, 刘劲松, 高月忠. 基于风廓线雷达资料的暴雨 天气过程分析 [J].气象科技. 2009(04)

[6]王令, 康玉霞, 焦热光, 市素芬, 丁青兰. 北京地区强对 流天气雷达回波特征 [J].气象. 2004 (07)

[7]张否. C 波段双线偏振雷达数据处理及其在粒子分类和 降水估测中的应用 [D]. 南京信息工程大学. 2017

[8]刘黎平. 双线偏振多普勒天气雷达估测混合区降雨和 降雹方法的理论研究 [J]. 大气科学. 2002 (06)

[9]刘黎平, 葛润生, 张沛源. 双线偏振多普勒天气雷达遥 测降水强度和液态含水量的方法和精度研究 [J]. 大 气科学. $2002(05)$ 